\title{
QUEEN'S
UNIVERSITY
BELFAST
}

\section{Visual cycle modulators versus placebo or observation for the prevention and treatment of geographic atrophy due to age-related}

macular degeneration

Yeong, J. L., Loveman, E., Colquitt, J. L., Royle, P., Waugh, N., \& Lois, N. (2018). Visual cycle modulators versus placebo or observation for the prevention and treatment of geographic atrophy due to age-related macular degeneration. Cochrane Database of Systematic Reviews, (10), [CD013154].

https://doi.org/10.1002/14651858.CD013154

\section{Published in:}

Cochrane Database of Systematic Reviews

\section{Document Version:}

Publisher's PDF, also known as Version of record

Queen's University Belfast - Research Portal:

Link to publication record in Queen's University Belfast Research Portal

\section{Publisher rights}

(c) 2018 The Cochrane Collaboration. This work is made available online in accordance with the publisher's policies. Please refer to any applicable terms of use of the publisher.

\section{General rights}

Copyright for the publications made accessible via the Queen's University Belfast Research Portal is retained by the author(s) and / or other copyright owners and it is a condition of accessing these publications that users recognise and abide by the legal requirements associated with these rights.

\section{Take down policy}

The Research Portal is Queen's institutional repository that provides access to Queen's research output. Every effort has been made to ensure that content in the Research Portal does not infringe any person's rights, or applicable UK laws. If you discover content in the Research Portal that you believe breaches copyright or violates any law, please contact openaccess@qub.ac.uk. 


\section{(E) Cochrane Library}

Cochrane Database of Systematic Reviews

\section{Visual cycle modulators versus placebo or observation for the prevention and treatment of geographic atrophy due to age- related macular degeneration (Protocol)}

Yeong JL, Loveman E, Colquitt JL, Royle P, Waugh N, Lois N

Yeong JL, Loveman E, Colquitt JL, Royle P, Waugh N, Lois N.

Visual cycle modulators versus placebo or observation for the prevention and treatment of geographic atrophy due to age-related macular degeneration.

Cochrane Database of Systematic Reviews 2018, Issue 10. Art. No.: CD013154.

DOI: 10.1002/14651858.CD013154.

www.cochranelibrary.com 


\section{TABLE OF CONTENTS}

HEADER . . . . . . . . . . . . . . . . . . . . . . . . . . . . . . . . . . . . . . . . 1

ABSTRACT . . . . . . . . . . . . . . . . . . . . . . . . . . . . . . . . . . . . . . 1

BACKGROUND . . . . . . . . . . . . . . . . . . . . . . . . . . . . . . . . . . 1

Figure 1. . . . . . . . . . . . . . . . . . . . . . . . . . . . . . . . . . . . . . 3

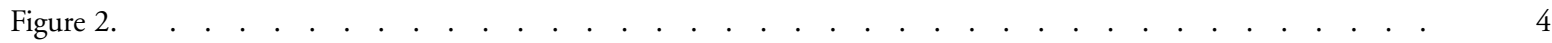

OBJECTIVES . . . . . . . . . . . . . . . . . . . . . . . . . . . . . . . . . . . . . . . . . . .

METHODS . . . . . . . . . . . . . . . . . . . . . . . . . . . . . . . . . . . . . . 5

ACKNOWLEDGEMENTS . . . . . . . . . . . . . . . . . . . . . . . . . . . . . . . . . .

REFERENCES . . . . . . . . . . . . . . . . . . . . . . . . . . . . . . . . . . . . . . 8

APPENDICES . . . . . . . . . . . . . . . . . . . . . . . . . . . . . . . . . . . . . . . . 10

CONTRIBUTIONS OF AUTHORS . . . . . . . . . . . . . . . . . . . . . . . . . . . . . . . . . . . .

DECLARATIONS OF INTEREST . . . . . . . . . . . . . . . . . . . . . . . . . . . . . . . . . . . . . 13

SOURCES OF SUPPORT . . . . . . . . . . . . . . . . . . . . . . . . . . . . . . . . . . . . . . . . . . . . .

Visual cycle modulators versus placebo or observation for the prevention and treatment of geographic atrophy due to age-related 


\title{
Visual cycle modulators versus placebo or observation for the prevention and treatment of geographic atrophy due to age- related macular degeneration
}

\author{
Jian Lee Yeong ${ }^{1}$, Emma Loveman $^{2}$, Jill L Colquitt ${ }^{2}$, Pamela Royle $^{3}$, Norman Waugh $^{4}$, Noemi Lois ${ }^{5}$ \\ ${ }^{1}$ Belfast and Social Care Trust, Royal Victoria Hospital, Belfast, UK. ${ }^{2}$ Effective Evidence LLP, Waterlooville, UK. ${ }^{3}$ Warwick Evidence, \\ Health Sciences Research Institute, Warwick Medical School, University of Warwick, Coventry, UK. ${ }^{4}$ Division of Health Sciences, \\ Warwick Medical School, University of Warwick, Coventry, UK. ${ }^{5}$ Wellcome-Wolfson Institute for Experimental Medicine, Queen's \\ University, Belfast, UK
}

Contact address: Noemi Lois, Wellcome-Wolfson Institute for Experimental Medicine, Queen's University, Belfast, UK. n.lois@qub.ac.uk.

Editorial group: Cochrane Eyes and Vision Group.

Publication status and date: New, published in Issue 10, 2018.

Citation: Yeong JL, Loveman E, Colquitt JL, Royle P, Waugh N, Lois N. Visual cycle modulators versus placebo or observation for the prevention and treatment of geographic atrophy due to age-related macular degeneration. Cochrane Database of Systematic Reviews 2018, Issue 10. Art. No.: CD013154. DOI: 10.1002/14651858.CD013154.

Copyright (C) 2018 The Cochrane Collaboration. Published by John Wiley \& Sons, Ltd.

\begin{abstract}
A B S T R A C T
This is a protocol for a Cochrane Review (Intervention). The objectives are as follows:

To assess the efficacy and safety of visual cycle modulators for the prevention and treatment of geographic atrophy.
\end{abstract}

\section{B A C K G R O U N D}

\section{Description of the condition}

Age-related macular degeneration (AMD), is a progressive chronic disease of the central retina (macula), typically affecting the elderly population (Joachim 2015; Klein 2007). AMD is a condition with a continuous spectrum that can be classified into early, intermediate and advanced stages (Ferris 2013). Both early and intermediate stages are characterised by the presence and size of drusen and by the presence or absence of pigmentary changes in the macula (Ferris 2013). Patients tend to be asymptomatic during these early stages ( $\operatorname{Lim}$ 2012). However, the central vision is severely affected as the condition progresses to advanced AMD, where geographic atrophy, or neovascular AMD (also known as exudative AMD), lead to the loss of photoreceptor cells (visual cells), at the macula. The severity of AMD is associated with increasing age, smoking, cardiovascular factors and genetics (Joachim 2015; Klein 2007; Lim 2012; Wong 2014).

Geographic atrophy is the most prevalent form of advanced AMD (Petrukhin 2007). It is defined as the presence of sharply demarcated atrophic lesions at the macula secondary to the loss of photoreceptors, retinal pigment epithelium (RPE), and choriocapillaris, causing loss of visual function (Fleckenstein 2017). It is typically a bilateral condition. The atrophic lesions tend to arise in the perifoveal regions initially, sparing the fovea ('foveal sparing'), before these lesions expand and coalesce over time to affect the fovea as well (Fleckenstein 2017).

Geographic atrophy can be observed clinically by slit-lamp biomi-

Visual cycle modulators versus placebo or observation for the prevention and treatment of geographic atrophy due to age-related 
croscopy and it can be documented by using multiple imaging modalities, with the most common being a combination of colour fundus photography, fundus autofluorescence imaging and optical coherence tomography. On autofluorescence, features of early and intermediate AMD can be determined (Lois 2002), and areas of geographic atrophy demonstrate reduced autofluorescence signal (Holz 2001; Schmitz-Valckenberg 2004). Often there is a zone with increased autofluorescence signal surrounding the area affected by geographic atrophy and it has been suggested that these zones are at higher risk for geographic atrophy expansion (Holz 2001; Schmitz-Valckenberg 2004).

The rate of progression for geographic atrophy is highly variable among individuals, ranging from 0.53 to $2.6 \mathrm{~mm}^{2} /$ year (Fleckenstein 2017; Holz 2007; Klein 2008; Lindblad 2009; Schmitz-Valckenberg 2016; Sunness 2007), depending on the technology used to determine geographic atrophy and also on various patient-related prognostic factors, including larger baseline lesion size, presence of multifocal lesions, specific autofluorescence patterns and parafoveal atrophic lesions (Fleckenstein 2017). It has been reported that the median time for parafoveal geographic atrophy to expand into the fovea is -2.5 years (Lindblad 2009).

The condition of the fellow eye is also considered to be an important prognostic tool for progression of geographic atrophy. Thus, people with unilateral geographic atrophy are at high risk of developing geographic atrophy in the fellow eye, with an estimated median time of seven years (Lindblad 2009). In addition, the rate of geographic atrophy progression is highest if the fellow eye has geographic atrophy, while it is lowest if the fellow eye has only early/intermediate AMD (Fleckenstein 2017).

People with geographic atrophy experience scotomas (visual field defects), corresponding to the atrophic areas, whilst central vision is preserved to varying degrees if the fovea is spared (Sunness 1995).
However, people will experience a drop in central visual acuity once the fovea is involved. In an observational study, 53\% of geographic atrophy participants (initially not involving the fovea), suffered a 3-line loss of visual acuity by four years. Eyes with better visual acuity were observed to have the highest rate of visual acuity loss, with $27 \%$ dropping from $6 / 15$ or better to $6 / 60$ or worse in four years (Sunness 1999).

\section{Description of the intervention}

In the visual cycle a series of enzymatic reactions take place in the RPE and photoreceptor cells of the retina which, together with events occurring in the phototransduction cascade, enable generation of sight (Kiser 2014). Vitamin A (all-trans-retinol (alltrans-ROL)), is an essential part of this process, and its deficiency causes nyctalopia (night blindness), among other symptoms.

The main chromophore in the retina is 11-cis-retinal (11-cisRAL), (Kiser 2014). It is normally bound to rhodopsin. When rhodopsin absorbs light, 11-cis-RAL undergoes isomerisation into all-trans-retinal (all-trans-RAL), and the rhodopsin becomes active, facilitating phototransduction (Kiser 2014). To enable continuous phototransduction, 11-cis-RAL is constantly recycled through the visual cycle (Figure 1). After all-trans-RAL is released from rhodopsin, it combines with phosphatidylethanolamine (PE), to form $\mathrm{N}$-retinylidine PE. This is then transported to the cytosolic side of the disc membrane via the ATP-binding cassette transporter of the retina (ABCR), where all-trans-retinol dehydrogenase (at-RDH), resides. There, all-trans-RAL is reduced by the at-RDH into all-trans-ROL, which will then enter the RPE and, through a series of enzymatic reactions is converted again into 11cis-RAL, which returns to the photoreceptors to be used again (Crouch 2009). 
Figure I. The visual cycle ABCR: ATP binding cassette of the retina; at-RDH: all-trans retinol dehydrogenase; RBP4-retinol-TTR: retinol binding protein-retinol- transthyretin complex; LRAT: lecithin-retinol acyltransferase; all-trans-RE: all-trans-retinyl ester; 11-cis-RDH: I I-cis-retinol dehydrogenase

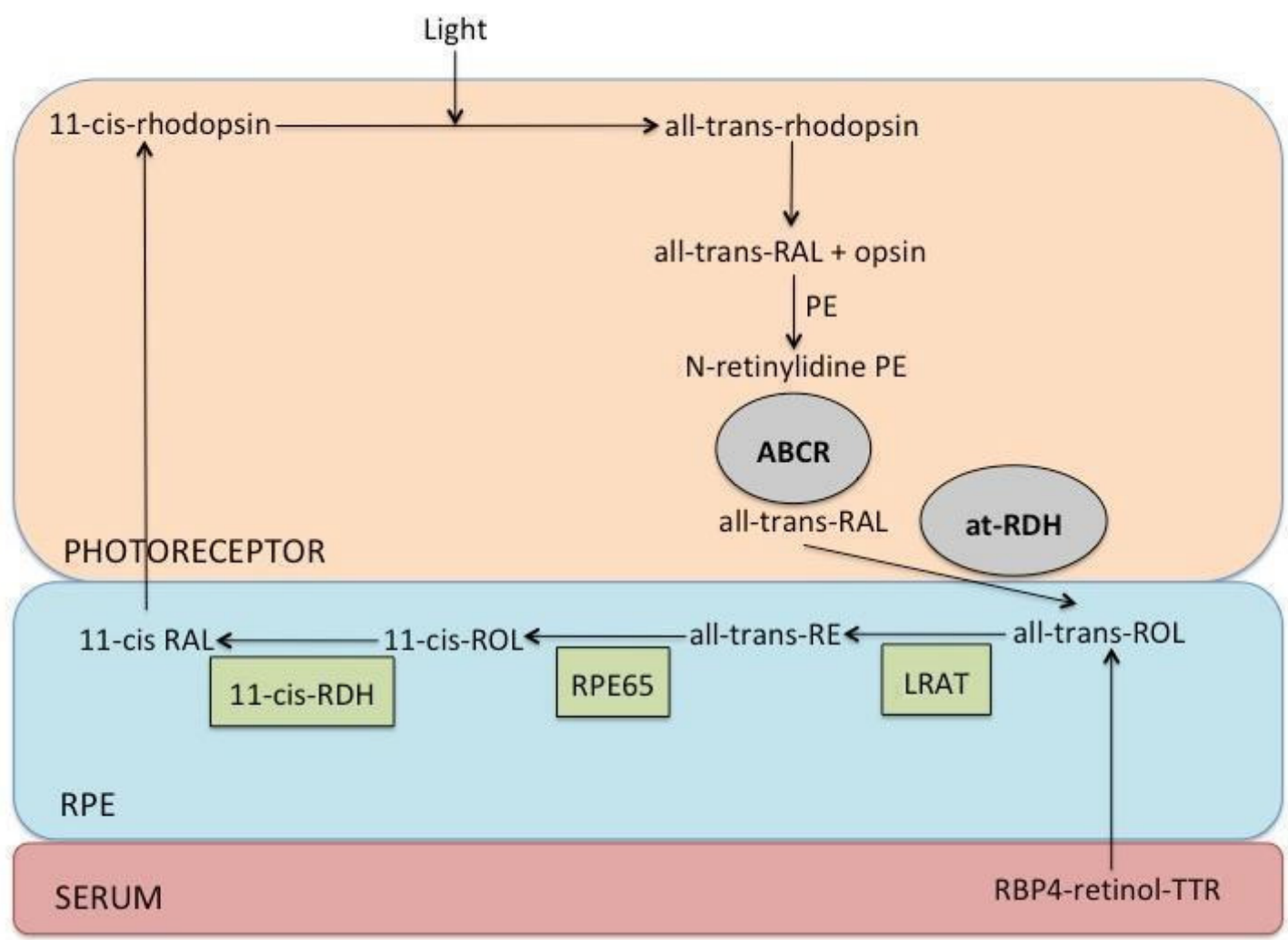

Visual cycle modulators are pharmacologic agents that slow down the visual cycle. This can be achieved through various mechanisms (Figure 2). 
Figure 2. N-retinylidene-N-retinylethanolamine (A2E) formation and mechanism of action of various visual cycle inhibitors (VCls)

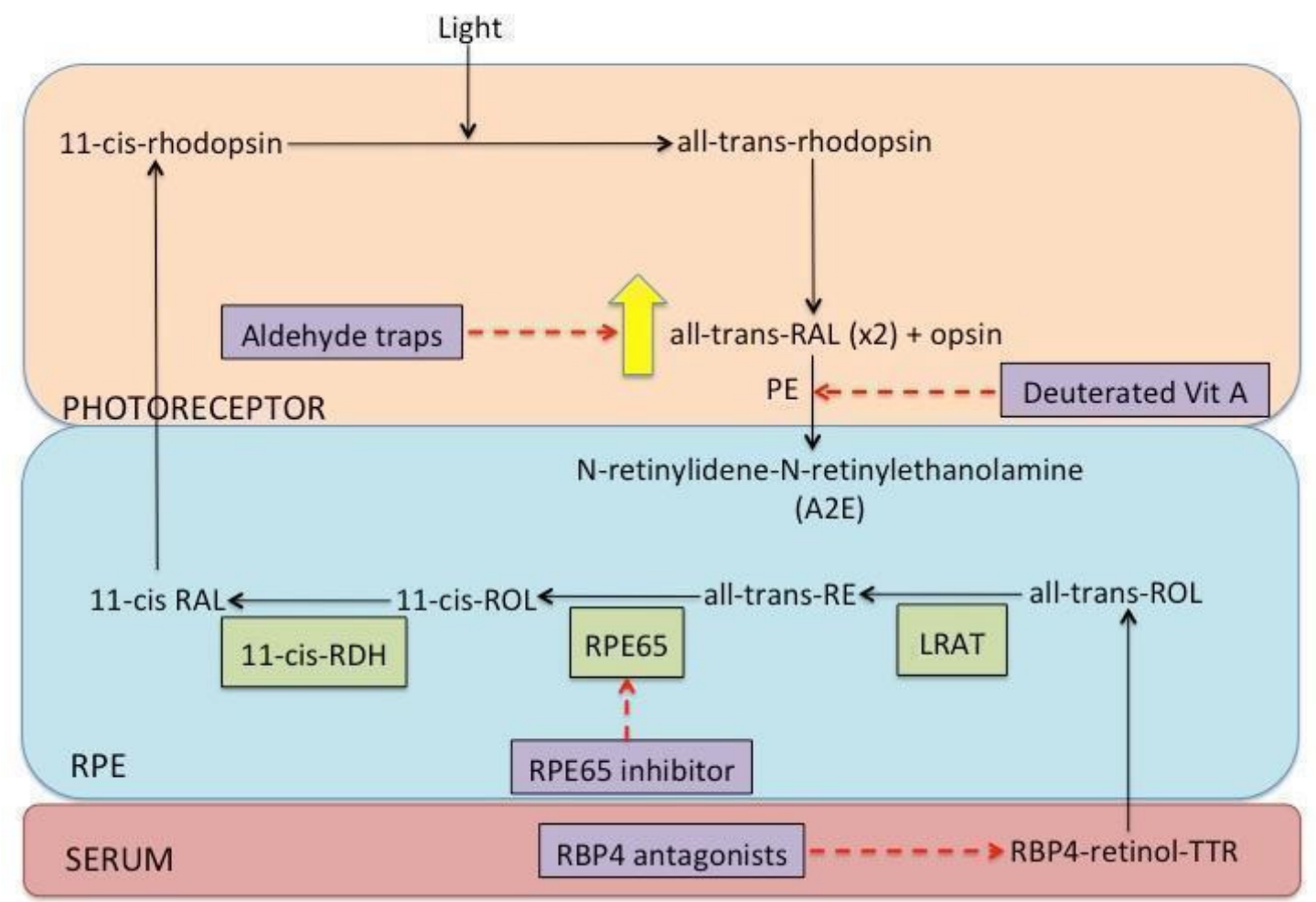

- Inhibition of key visual cycle enzymes

- Retinol binding protein 4 (RBP4), antagonists

- Scavengers of free all-trans-RAL (aldehyde traps)

- Deuterated vitamin A

\section{How the intervention might work}

Several pathogenic mechanisms may be involved in the occurrence and progression of geographic atrophy, of which accumulation of lipofuscin (wear and tear pigment), in the RPE is probably one of those most widely accepted (Dorey 1989; Holz 2001; Schmitz-Valckenberg 2004). The major and best-characterised component of lipofuscin is $\mathrm{N}$-retinylidene- $\mathrm{N}$-retinylethanolamine (A2E), (Dugel 2015; Sparrow 2003). A2E is formed when two molecules of all-trans-RAL react with PE (Figure 2). It has been proposed that with ageing, RPE cell loss causes an increase in phagocytic load of metabolic waste products from photoreceptor disc membranes. The inefficiency of RPE cells to clear these waste products causes an accumulation of free all-trans-RAL, thus increasing formation of A2E (Dorey 1989; Sparrow 2003). A2E damages the RPE through generating reactive oxygen species, causing dysfunction in the protein transportation of the cells, complement activation, up-regulation of vascular endothelial growth factor (VEGF), and inducing premature cell death (Bavik 2015). In order to reduce $\mathrm{A} 2 \mathrm{E}$ and lipofuscin formation, slowing down the visual cycle by pharmacologic means has been proposed as an option for reducing progression and prevention of geographic atrophy (Hanus 2016).

One of the key visual cycle enzymes, RPE65 converts all-trans-RE to 11-cis-ROL, which is then reduced to 11-cis-RAL. In a study utilising ABCR knockout mice (known to cause excess lipofuscin generation in the retina similar to Stargardt's disease), it was observed that treatment with an RPE65 inhibitor (emixustat), for three months, caused a reduction of $\mathrm{A} 2 \mathrm{E}$ formation by approximately 60\% compared with controls (Bavik 2015). The effect was dose-dependent.

The supply of retinol is key to the visual cycle. In the body, serum retinol is normally bound to RBP4 to form the retinol-RBP4transthyretin (TTR), complex to prevent rapid renal elimination. 
RBP4 needs to bind with retinol in order to activate binding with TTR (Petrukhin 2013). RBP4 antagonists (fenretinide and A1120), act by displacing retinol from RBP4 and thus disrupting the formation of retinol-RBP4-TTR complex and leading to the loss of retinol through the urine (Dobri 2013; Radu 2005). Intraperitoneal administration of fenretinide for 28 days and oral administration of A1120 for six weeks in ABCR knockout mice have shown a dose dependent reduction of A2E levels (Dobri 2013; Radu 2005). This was correlated with reduced autofluorescence levels when the fenretinide-administered mice were examined post-mortem (Radu 2005).

Another way proposed to reduce A2E production is by trapping free all-trans-RAL in the photoreceptors by utilising primary amine-containing drugs. These serve as a direct competitor of PE to bind with free all-trans-RAL (Maeda 2011). In a study conducted with ABCR and at-RDH-deficient mice, certain Food and Drug Administration (FDA) approved drugs containing primary amines were shown to protect against light-induced retinal damage as proven on optical coherence tomography and post-mortem histology analysis (Maeda 2011).

Deuterium is a stable and non-radioactive isotope commonly used as metabolic and pharmacokinetic probe in studies (Petrukhin 2013). By incorporating deuterium to the carbon-20 position of vitamin $\mathrm{A}\left(\mathrm{C} 20-\mathrm{D}_{3}\right.$-vitamin $\left.\mathrm{A}\right)$, a resultant primary kinetic isotope effect is created that slows down the visual cycle, and thus reduces $\mathrm{A} 2 \mathrm{E}$ production. This was observed in a study where wildtype mice fed with $\mathrm{C} 20-\mathrm{D}_{3}$-vitamin A for six weeks showed reduced A2E levels compared with controls that consumed a normal vitamin A diet (Kaufman 2011).

Currently there are published randomised controlled trials evaluating visual cycle modulators for geographic atrophy, including emixustat and fenretinide, both phase 2 trials. These medications are delivered orally and appeared to be safe. Fenretinide, for example, has been used widely to treat different types of cancer and has been shown to be safe after many years of continuous treatment. The duration of treatment for visual cycle modulators is unknown at present but we expect that likely a life-long treatment may be needed in a progressing condition such as AMD.

\section{Why it is important to do this review}

AMD is the most common cause of blindness in high-income countries and third most common in the world, with $8.7 \%$ of the world's population affected by this disease (WHO 2002; Wong 2014). The number of affected individuals is projected at 196 million in 2020 and 288 million in 2040 as a result of an increasingly ageing population (Wong 2014). Visual impairment secondary to AMD is associated with reduced quality of life (Lamoureux 2011), and higher economic burden, costing the USA USD 575 to 733 million in total (Rein 2006).

With the introduction of anti-VEGF therapy, there are currently well-established treatment regimes for neovascular AMD, which have been proven to stabilise and even improve vision in people affected by this disorder. (Brown 2006; Rosenfeld 2006). However, the search for effective treatments for geographic atrophy continues.

As geographic atrophy is a slow and progressive condition, there is time for intervention before the retina is destroyed and certainly before the central fovea is affected, causing deterioration in central visual acuity. In addition, autofluorescence provides an accurate and validated method to monitor geographic atrophy progression, allowing clinicians and researchers to determine the efficacy of potential interventions.

Given the projected increasing prevalence of AMD and its associated burden, it is of the utmost importance to develop therapies for the treatment and prevention of geographic atrophy. With better understanding of the pathogenesis of AMD, many newer therapies are being investigated with variable results (Hanus 2016). Among these are visual cycle modulators, which are the subject of this Cochrane Review, which aims at determining the effect of visual cycle modulators for the treatment and prevention of geographic atrophy.

\section{O B J E C T I VES}

To assess the efficacy and safety of visual cycle modulators for the prevention and treatment of geographic atrophy.

\section{METHODS}

\section{Criteria for considering studies for this review}

\section{Types of studies}

We will include randomised and quasi-randomised clinical studies. As visual cycle modulator use for treatment/prevention of geographic atrophy is a relatively new method, randomised clinical studies on people with geographic atrophy might be sparse. We have decided to include quasi-randomised studies, as they will still provide useful information despite their limitations.

Studies published as abstracts or conference presentations will only be included if sufficient details are presented to allow an appraisal of the methodology and the assessment of results to be undertaken. This might occur if a protocol for the study has been published previously.

\section{Types of participants}

People diagnosed with AMD (early, intermediate or advanced $A M D$ ), using validated methods/classifications (identified 
through either, or a combination of, clinical examination, fundus photography, fundus autofluorescence imaging, angiography or optical coherence tomography), with no age, gender or ethnicity restrictions. In participants with advanced AMD, we will only include those with the atrophic form of the disease (geographic atrophy).

\section{Types of interventions}

The main intervention will be visual cycle modulators, which might be known as visual cycle inhibitors or by their mechanisms of action or by their drug name in the literature. This will include but is not limited to: emixustat (ACU-4429), fenretinide, A1120 (a non-retinoid RBP4 antagonist), and ALK-001 (C20-D 3 -Vita$\min \mathrm{A})$. There may be other drugs at earlier stages in development that cannot yet be evaluated. These will be noted for assessment, if possible, in future updates of this review.

The comparator will be placebo or no treatment (observation).

\section{Types of outcome measures}

\section{Primary outcomes}

Mean change in best-corrected visual acuity (BCVA), from baseline to month 24 .

\section{Secondary outcomes}

We will determine the following outcomes at 24 months.

- Percentage of people losing 15 letters or more of BCVA

- Percentage of people losing 10 letters or more of BCVA

- Percentage of people losing 5 letters or more of BCVA

- Progression (growth of existing or development of new areas), of geographic atrophy (as measured using either, or a combination of, fundus photography, fundus autofluorescence or fluorescein angiography). The mean geographic atrophy progression rate $\left(\mathrm{mm}^{2} /\right.$ year$)$, measured using either fundus autofluorescence or colour fundus photography must have a difference of more than $0.02 \mathrm{~mm}^{2}$ across groups to be considered a relevant difference beyond potential variability in the measures of geographic atrophy (Domalpally 2016).

- Progression to advanced AMD (geographic atrophy or neovascular AMD), in prevention studies including participants with early or intermediate AMD.

- Mean change in macular sensitivity, as measured with macular microperimetry, in prevention studies including participants with early or intermediate AMD.

If a study does not have a follow-up period of up to 24 months, we will take the last result at the end of the study to compare it to baseline for all the above parameters.

\section{Adverse effects}

We will investigate ocular, systemic adverse effects and serious adverse effects (e.g. all-cause death, serious systemic adverse events), observed in treatment and comparator groups.

\section{Search methods for identification of studies}

\section{Electronic searches}

We will search the following electronic databases for randomised controlled trials and controlled clinical trials:

- Cochrane Central Register of Controlled Trials (CENTRAL), (which contains the Cochrane Eyes and Vision Trials Register), in the Cochrane Library (latest issue);

- MEDLINE Ovid (1946 to present);

- Embase (1947 to present);

- Web of Science (1970 to present);

- Scopus (1960 to present);

- UK Clinical Trials gateway;

- US National Institutes of Health Ongoing Trials Register ClinicalTrials.gov (www.clinicaltrials.gov);

- World Health Organization ( WHO), International Clinical Trials Registry Platform ( ICTRP), ( www.who.int/ ictrp).

The search will cover 2005 to the present date and there will be no language restrictions. We will adapt the Ovid Medline search strategy as appropriate to other databases (Appendix 1).

\section{Searching other resources}

We will check reference lists of reviews and existing studies for relevant studies and use the Cited Reference Search function in the Web of Science to identify articles that have cited studies identified for inclusion in the review. We will consult clinical experts for any other relevant literature. We will search The Association for Research in Vision and Ophthalmology (ARVO), website from 2005 to the present date to identify any further relevant studies.

\section{Data collection and analysis}

\section{Selection of studies}

Two review authors will independently screen titles and abstracts retrieved from the searches to identify all citations that appear likely to meet the inclusion criteria. In general, citations considered not relevant at this stage will not be documented in the review other than to note the number of these in a flow chart (Moher 2009). One review author will retrieve the full manuscripts of relevant studies and assess them for eligibility, and a second review 
author will check them. We will document studies excluded after full-text review.

We will resolve any disagreements between the two review authors by discussion or by arbitration by a third review author if needed. We will not mask the names of the authors, institutions, or journals when reviewing studies.

\section{Data extraction and management}

One review author will extract data from the included studies using a standard data extraction form and a second review author will check the data extracted. We will extract data related to study characteristics (Appendix 2), study methods and outcomes. We will resolve any discrepancies or disagreements by discussion or by arbitration from a third review author if needed. We will contact study authors for missing or unclear data. One review author will enter the data into Review Manager 5 (Review Manager 2014), and a second review author will check the data for inaccuracies.

\section{Assessment of risk of bias in included studies}

We will use the Cochrane 'Risk of bias' checklist. One review author will assess the included studies for risk of bias and a second review author will check the 'Risk of bias' assessment. We will assess the following domains for each included study as described in Chapter 8 of the Cochrane Handbook for Systematic Review of Interventions (HiggIns 2017).

- Selection bias: sequence generation and allocation concealment

- Performance bias: masking of participants and personnel

- Detection bias: masking of outcome assessment

- Attrition bias: incomplete outcome data

- Reporting bias: selective outcome reporting. If the protocol or clinical trials registry record for the included study is available, we will evaluate the study for evidence of systematic differences between reported and unreported findings.

We will assess each 'Risk of bias' domain as low, high, or unclear and provide descriptions as to our reasoning for such assessments. We will resolve disagreements by discussion or by consulting a third review author when necessary.

\section{Measures of treatment effect}

We will calculate the mean difference with $95 \%$ confidence intervals for outcome measures reported as continuous data (mean change in BCVA, mean change in area of geographic atrophy). We will calculate the risk ratio with $95 \%$ confidence intervals for outcome measures reported as dichotomous data (proportion with loss of BCVA, progression to advanced AMD, adverse events).

\section{Unit of analysis issues}

We anticipate that most of the included studies will have randomised a single eye per participant to a single intervention. We will also consider the participant as the unit of analysis when both eyes of a single participant are randomised and analysed as a unit. In the case where both eyes of participants are included and analysed with the eye as the unit of analysis, we will attempt to analyse the data adjusting for clustering or paired-eye design as appropriate and as described in the Cochrane Handbook for Systematic Reviews of Interventions (Deeks 2017).

\section{Dealing with missing data}

In the case of missing data we will contact study authors to try to obtain these data. We will allow study authors one month to respond, with a reminder two weeks after initial contact in absence of a response. If such attempts are unsuccessful, we will perform the analysis using the available data. We will not impute data for the purposes of this review.

\section{Assessment of heterogeneity}

We will assess included studies for clinical, methodological, and statistical heterogeneity. When no substantial clinical or methodological heterogeneity is identified, we will combine studies in meta-analysis. We will look at the consistency across studies by examining the value of the $\mathrm{I}^{2}$ statistic (Higgins 2003), the direction of effects, and the overlap of confidence intervals on the forest plot. We will consider $\mathrm{I}^{2}$ values greater than $60 \%$ to represent substantial statistical heterogeneity. Differences in the direction of effects and poor overlap of confidence intervals among studies also suggest heterogeneity among studies (Deeks 2017).

\section{Assessment of reporting biases}

We will assess publication bias with the funnel plot and Egger's regression intercept when 10 or more studies are included in a meta-analysis. We will assess for potential selective outcome reporting by study as part of the 'Risk of bias' assessment (Egger 1997; Sterne 2017).

\section{Data synthesis}

When data are sufficient and no substantial clinical, methodological, and statistical heterogeneity are identified in the above assessment, we will conduct meta-analysis using a random-effects model. If fewer than three studies are included in a meta-analysis, we will use a fixed-effect model. If we determine that conducting a meta-analysis is inappropriate due to heterogeneity, we will report a narrative or tabulated summary. We will use $95 \%$ confidence intervals throughout. 


\section{Subgroup analysis and investigation of heterogeneity}

We will analyse studies undertaken to evaluate prevention of atrophic AMD in participants with early or intermediate forms of the diseases separately from those undertaken to evaluate treatment of people with already established geographic atrophy.

\section{Sensitivity analysis}

We will perform the following sensitivity analyses on the primary outcome:

- excluding studies defined as 'high risk' of bias in one or more domains based on the Cochrane 'Risk of bias' checklist;

- comparing fixed-effect and random-effects models (if there are three or more studies)

\section{GRADE and 'Summary of findings' table}

Where there is sufficient evidence, we will prepare a 'Summary of findings' table to present estimated relative and absolute risks (GRADEpro GDT). Two review authors will independently grade the overall quality of the evidence for each outcome using the GRADE classification (Guyatt 2008). We will include the following outcomes in the 'Summary of findings' table at 24 months (Schünemann 2017).
- Mean change in BCVA

- Proportion losing 15 letters of BCVA

- Proportion losing 10 letters of BCVA

- Progression of geographic atrophy

- Progression to advanced AMD (geographic atrophy or neovascular AMD)

- Mean change in macular sensitivity

- Adverse events: all-cause mortality, all serious systemic adverse events

We will use the five GRADE considerations (risk of bias, consistency of effect, imprecision, indirectness and publication bias), grading the evidence for each outcome as high, moderate, low, or very low. We will justify all decisions to down- or up-grade the quality of studies using footnotes and comments to aid the reader's understanding of the review where appropriate.

\section{ACKNOWLEDGEMENTS}

We thank Tim Jackson for peer review comments on this protocol and Jennifer Evans and Anupa Shah from Cochrane Eyes and Vision for their assistance with the protocol.

\section{R E F E R E N C E S}

\section{Additional references}

\section{Bavik 2015}

Bavik C, Henry SH, Zhang Y, Mitts K, McGinn T, Budzynski E, et al. Visual cycle modulation as an approach toward preservation of retinal integrity. PLoS One 2015;10 (5):e0124940.

Brown 2006

Brown DM, Kaiser PK, Michels M, Soubrane G, Heier JS, Kim RY, et al. Ranibizumab versus verteporfin for neovascular age-related macular degeneration. New England Journal of Medicine 2006;355(14):1432-44.

\section{Crouch 2009}

Crouch RK. The visual cycle: generation of 11-cis retinal for photoreceptors. photobiology.info/Crouch.html (accessed 24 July 2018).

\section{Deeks 2017}

Deeks JJ, Higgins JP, Altman DG (editors) on behalf ofthe Cochrane Statistical Methods Group. Chapter 9: Analysing data and undertaking meta-analyses. In: Higgins JPT, Churchill R, Chandler J, Cumpston MS (editors), Cochrane Handbook for Systematic Reviews of Interventions version 5.2.0 (updated June 2017), Cochrane, 2017. Available from www.training.cochrane.org/handbook.
Dobri 2013

Dobri N, Qin Q, Kong J, Yamamoto K, Liu Z, Moiseyev G, et al. A1120, a nonretinoid RBP4 antagonist, inhibits formation of cytotoxic bisretinoids in the animal model of enhanced retinal lipofuscinogenesis. Investigative Ophthalmology and Visual Science 2013;54(1):85-95.

Domalpally 2016 Domalpally A, Danis R, Agron E, Blodi B, Clemons T, Chew E, et al. Evaluation of geographic atrophy from color photographs and fundus autofluorescence images: Age-Related Eye Disease Study 2 report number 11. Ophthalmology 2016;123(11):2401-07.

Dorey 1989

Dorey CK, Wu G, Ebenstein D, Garsd A, Weiter JJ. Cell loss in the aging retina. Relationship to lipofuscin accumulation and macular degeneration. Investigative Ophthalmology and Visual Science 1989;30(8):1691-9.

Dugel 2015

Dugel P, Novack R, Csaky K, Richmond P, Birch D, Kubota R. Phase II, randomized, placebo-controlled, 90-day study of emixustat hydrochloride in geographic atrophy associated with dry age-related macular degeneration. Retina 2015;35 (6):1173-83.

Egger 1997

Egger M, Smith GD, Schneider M, Minder C. Bias in 
meta-analysis detected by a simple, graphical test. $B M J$ 1997;315:629-34.

\section{Ferris 2013}

Ferris FL 3rd, Wilkinson CP, Bird A, Chakravarthy U, Chew E, Csaky K, et al. Clinical classification of agerelated macular degeneration. Ophthalmology 2013;120(4): $844-51$.

\section{Fleckenstein 2017}

Fleckenstein M, Mitchell P, Fruend KB, Sadda S, Holz FG, Brittain C, et al. The progression of geographic atrophy secondary to age-related macular degeneration. Ophthalmology 2017;125(3):369-90.

\section{GRADEpro GDT [Computer program]}

McMaster University (developed by Evidence Prime). GRADEpro GDT. Version accessed prior to 3 August 2018. Hamilton (ON): McMaster University (developed by Evidence Prime), 2015.

\section{Guyatt 2008}

Guyatt GH, Oxman AD, Vist GE, Kunz R, Falck-Ytter Y, Alonso-Coello P, et al. GRADE: an emerging consensus on rating quality of evidence and strength of recommendations. BMJ 2008;336:924-6.

\section{Hanus 2016}

Hanus J, Zhao F, Wang S. Current therapeutic developments in atrophic age-related macular degeneration. British Journal of Ophthalmology 2016;100(1):122-7.

\section{Higgins 2003}

Higgins JP, Thompson SG, Deeks JJ, Altman DG. Measuring inconsistency in meta-analyses. BMJ 2003;327: 557-60.

HiggIns 2017

Higgins JPT, Altman DG, Sterne JAC editor(s). Chapter 8: Assessing risk of bias in included studies. In: Higgins JPT, Churchill R, Chandler J, Cumpston MS (editors), Cochrane Handbook for Systematic Reviews of Interventions version 5.2.0 (updated June 2017), Cochrane, 2017. Available from www.training.cochrane.org/handbook.

\section{Holz 2001}

Holz FG, Bellman C, Staudt S, Schutt F, Volcker HE. Fundus autofluorescence and development of geographic atrophy in age-related macular degeneration. Investigative Ophthalmology and Visual Science 2001;42(5):1051-6.

\section{Holz 2007}

Holz FG, Bindewald-Wittich A, Fleckenstein M, Dreyhaupt J, Scholl HP, Schmitz-Valckenberg S, et al. Progression of geographic atrophy and impact of fundus autofluorescence patterns in age-related macular degeneration. American Journal of Ophthalmology 2007;143(3):463-72.

\section{Joachim 2015}

Joachim N, Mitchell P, Burlutsky P, Kifley A, Wang JJ. The incidence and progression of age-related macular degeneration over 15 years: the Blue Mountains Eye Study. Ophthalmology 2015;122(12):2482-9.

\section{Kaufman 2011}

Kaufman Y, Ma L, Washington I. Deuterium enrichment of Vitamin A at the C20 position slows the formation of detrimental Vitamin A dimers in wild-type rodents. Journal of Biological Chemistry 2011;286(10):7958-65.

\section{Kiser 2014}

Kiser PD, Golczak M, Palczewski K. Chemistry of the retinoid (visual) cycle. Chemical Reviews 2014;114(1): 194-232.

\section{Klein 2007}

Klein R, Klein BE, Knudtson MD, Meuer SM, Swift M, Gangnon RE. Fifteen-year cumulative incidence of agerelated macular degeneration: the Beaver Dam Eye Study. Ophthalmology 2007;114(2):253-62.

\section{Klein 2008}

Klein R, Meuer SM, Knudtson MD, Klein BE. The epidemiology of progression of pure geographic atrophy: the Beaver Dam Eye Study. American Journal of Ophthalmology 2008;146(5):692-9.

\section{Lamoureux 2011}

Lamorouex EL, Mitchell P, Rees G, Cheung G, Yeo L, Lee SY, et al. Impact of early and late age-related macular degeneration on vision-specific functioning. British Journal of Ophthalmology 2011;95(5):666-70.

Lim 2012

Lim LS, Mitchell P, Seddon JM, Holz FG, Wong TY. Agerelated macular degeneration. Lancet 2012;379(9827): 1728-38.

\section{Lindblad 2009}

Lindblad AS, Lloyd PC, Clemons TE, Gensler GR, Ferris FL 3rd, Klein ML, et al. Change in area of geographic atrophy in the Age-Related Eye Disease Study: AREDS report number 26. Archives of Ophthalmology 2009;127(9): 1168-74.

\section{Lois 2002}

Lois N, Owens SL, Coco R, Hopkins J, Fitzke FW, Bird AC. Fundus autofluorescence in patients with age-related macular degeneration and high risk of visual loss. American Journal of Ophthalmology 2002;133(3):341-9.

\section{Maeda 2011}

Maeda A, Golczak M, Chen Y, Okano K, Kohno H, Shiose $S$, et al. Primary amines protect against retinal degeneration in mouse models of retinopathies. Nature Chemical Biology $2011 ; 8(2): 170-8$

Moher 2009

Moher D, Liberati A, Tetzlaff J, Altman DG, PRISMA Group (2009). Preferred reporting items for systematic reviews and meta-analyses: the PRISMA Statement. PLoS Medicine 6;7:e1000097. DOI: 10.1371/ journal.pmed 1000097

\section{Petrukhin 2007}

Petrukhin K. New therapeutic targets in atrophic age-related macular degeneration. Expert Opinion on Therapeutic Targets 2007;11(5):625-39. 


\section{Petrukhin 2013}

Petrukhin K. Pharmacological inhibition of lipofuscin accumulation in the retina as a therapeutic strategy for dry AMD treatment. Drug Discovery Today: Therapeutic Strategies 2013;10(1):e11-e20.

\section{Radu 2005}

Radu RA, Han Y, Bui TV, Nusinowitz S, Bok D, Lichter J, et al. Reductions in serum vitamin A arrest accumulation of toxic retinal fluorophores: a potential therapy for treatment of lipofuscin-based retinal diseases. Investigative Ophthalmology and Visual Science 2005;46(12):4393-401.

\section{Rein 2006}

Rein DB, Zhang P, Wirth KE, Lee PP, Hoerger TJ, McCall $\mathrm{N}$, et al. The economic burden of major adult visual disorders in the United States. Archives of Ophthalmology 2006;124(12):1754-60.

Review Manager 2014 [Computer program] Nordic Cochrane Centre, The Cochrane Collaboration. Review Manager 5 (RevMan 5). Version 5.3. Copenhagen: Nordic Cochrane Centre, The Cochrane Collaboration, 2014.

\section{Rosenfeld 2006}

Rosenfeld PJ, Brown DM, Heier JS, Boyer DS, Kaiser PK, Chung CY, et al. Ranibizumab for neovascular age-related macular degeneration. New England Journal of Medicine 2006;355(14):1419-31.

\section{Schmitz-Valckenberg 2004}

Schmitz-Valckenberg S, Bultmaan S, Dreyhaupt J, Bindewald A, Holz FG, Rohrschneider K. Fundus autofluorescence and fundus perimetry in the junctional zone of geographic atrophy in patients with age-related macular degeneration. Investigative Ophthalmology and Visual Science 2004;45(12):4470-6.

\section{Schmitz-Valckenberg 2016}

Schimtz-Valckenberg S, Sahel JA, Danis R, Fleckenstein M, Jaffe GJ, Wolf S, et al. Natural history of geographic atrophy progression secondary to age-related macular degeneration (geographic atrophy progression study). Ophthalmology 2016;123(2):361-8.

\section{Schünemann 2017}

Schünemann HJ, Oxman AD, Higgins JP, Vist GE, Glasziou P, Akl E, et al. on behalf of the Cochrane GRADEing Methods Group and the Cochrane Statistical Methods Group. Chapter 11: Completing 'Summary of findings' tables and grading the confidence in or quality of the evidence. In: Higgins JPT, Churchill R, Chandler J, Cumpston MS (editors), Cochrane Handbook for Systematic Reviews of Interventions version 5.2.0 (updated June 2017). Cochrane, 2017. Available fromwww.training.cochrane.org/handbook.

\section{Sparrow 2003}

Sparrow JR, Fishkin N, Zhou J, Cai B, Jang YP, Krane S, et al. A2E, a byproduct of the visual cycle. Vision Research 2003;43(28):2983-90.

Sterne 2017

Sterne JA, Egger M, Moher D, Boutron I (editors). Chapter10: Addressing reporting biases. In: Higgins JPT, Churchill R, Chandler J, Cumpston MS (editors), Cochrane Handbook for Systematic Reviews of Interventions version 5.2.0 (updated June 2017), Cochrane, 2017. Available fromwww.training.cochrane.org/handbook.

\section{Sunness 1995}

Sunness JS, Schuchard RA, Shen N, Rubin GS, Dagnelie G, Haselwood DM. Landmark-driven fundus perimetry using the scanning laser ophthalmoscope. Investigative Ophthalmology and Visual Science 1995;36(9):1863-74.

\section{Sunness 1999}

Sunness JS, Gonzalez-Baron J, Applegate CA, Bressler NM, Tian Y, Hawkins B, et al. Enlargement of atrophy and visual acuity loss in the geographic atrophy form of agerelated macular degeneration. Ophthalmology 1999;106(9): 1768-79.

\section{Sunness 2007}

Sunness JS, Margalit E, Srikumaran D, Applegate CA, Tian Y, Perry D, et al. The long-term natural history of geographic atrophy from age-related macular degeneration: enlargement of atrophy and implications for interventional clinical trials. Ophthalmology 2007;114(2):271-7.

\section{WHO 2002}

World Health Organization. Causes of blindness and visual impairment. www.who.int/blindness/causes/en/ (accessed prior to 3 August 2018).

\section{Wong 2014}

Wong WL, Su X, Li X, Cheung CM, Klein R, Cheng CY, et al. Global prevalence of age-related macular degeneration and disease burden projection for 2020 and 2040: a systematic review and meta-analysis. Lancet Global Health 2014;2(2):106-16.

* Indicates the major publication for the study 


\section{A P P E N D I C E S}

\section{Appendix I. Ovid MEDLINE search strategy}

1. (age related macular degeneration or age related maculopathy or AMD or ARMD or geographic atrophy).tw.

2. exp Macular Degeneration/

3. exp Geographic Atrophy/

4. 1 or 2 or 3

5. exp *Enzyme Inhibitors/

6. retinol binding protein*.mp.

7. (fenretidine or fenofibrate or emixustat).mp.

8. (visual cycle adj3 (inhibit* or modulat*)).mp.

9. RBP4 antagonist*.tw.

10.5 or 6 or 7 or 8 or 9

11.4 and 10

12. exp Geographic Atrophy/

13. geographic atrophy.tw.

14. (atrophic adj (age-related macular degeneration or AMD)).tw.

15. 12 or 13 or 14

16. 11 or 15

17. randomized controlled trial.pt.

18. controlled clinical trial.pt.

19. (random* or trial or group* or control or placebo).tw.

20. 17 or 18 or 19

21. 16 and 20

22. Animals/

23. Humans/

24. 22 not 23

25. 21 not 24

26. (letter or comment or editorial).pt.

27. 25 not 26

28. limit 27 to $y r=" 2005$-Current"

\section{Appendix 2. Data on study characteristics}

Mandatory items

\section{Methods}

Study design
- Parallel group RCTi.e. people randomised to treatment

- Within-person RCTi.e. eyes randomised to treatment

- Cluster RCTi.e. communities randomised to treatment

- Cross-over RCT

- Other, specify

Optional items

Exclusions after randomisation Losses to follow-up Number randomised/analysed How were missing data handled? e.g., available case analysis, imputation methods Reported power calculation ( $\mathrm{Y} / \mathrm{N})$, if yes, sample size and power Unusual study design/issues 
Eyes or

Unit of randomisation/ unit of analysis
- One eye included in study, specify how eye selected

- Two eyes included in study, both eyes received same treatment, briefly specify how analysed (best/worstlaveragel both and adjusted for within person correlation/both and not adjusted for within person correlation) and specify if mixture one eye and two eye

- Two eyes included in study, eyes received different treatments,specify if correct pair-matched analysis done

\section{Participants}

\begin{tabular}{l|l} 
Country & $\begin{array}{l}\text { Setting } \\
\text { Ethnic group } \\
\text { Total number of participants }\end{array}$ \\
\hline Number (\%) of men and women & $\begin{array}{l}\text { This information should be collected for total } \\
\text { study population recruited into the study. If } \\
\text { these data are only reported for the people who } \\
\text { were followed up only, please indicate. }\end{array}$ \\
\hline Average age and age range & \\
\hline Inclusion criteria & \\
\hline Exclusion criteria & \\
\hline
\end{tabular}

\section{Interventions}

Intervention $(\mathrm{n}=)$

Comparator $(\mathrm{n}=)$

See MECIR 65 and 70
- Number of people randomised to this group

- Drug (or intervention) name

- Dose

- Frequency

- Route of administration

\section{Outcomes}

Primary and secondary outcomes as defined List outcomes in study reports Adverse events reported $(\mathrm{Y} / \mathrm{N})$

Planned/actual length of follow-up

See MECIR R70 Length of follow-up and intervals at which outcomes assessed

\section{Notes}

Date conducted

Specify dates of recruitment of participants $\mathrm{mm} / \mathrm{yr}$ to $\mathrm{mm} / \mathrm{yr}$
Full study name: (if applicable) Reported subgroup analyses $(\mathrm{Y} / \mathrm{N})$ Were trial investigators contacted? 


\section{CONTRIBUTIONSOFAUTHORS}

All the review authors contributed to and approved the protocol.

JLY: wrote the background information, objectives and original drawing of diagrams.

EL, JLC: wrote the methodology section, apart from the literature search strategy.

PR: created the literature search strategy.

NW, NL: conceived the project.

\section{DECLARATIONSOF INTEREST}

JLY: none known

EL: none known

JLC: none known

PR: none known

NW: none known

NL: none known

\section{SOURCES OF SUPPORT}

\section{Internal sources}

- No sources of support supplied

\section{External sources}

- National Institute for Health Research (NIHR), UK.

- Richard Wormald, Co-ordinating Editor for Cochrane Eyes and Vision (CEV) acknowledges financial support for his CEV research sessions from the Department of Health through the award made by the National Institute for Health Research to Moorfields Eye Hospital NHS Foundation Trust and UCL Institute of Ophthalmology for a Specialist Biomedical Research Centre for Ophthalmology.

- This protocol was supported by the National Institute for Health Research, via Cochrane Infrastructure funding to the CEV UK editorial base.

The views and opinions expressed therein are those of the authors and do not necessarily reflect those of the Systematic Reviews Programme, NIHR, NHS or the Department of Health. 